\title{
Vocal cord hematoma: an unusual complication of dengue fever Vadivelu Tamilarasan ${ }^{a}$, Malapaka Rama Krishna Ravi Chandrab, Bangalore Venkatraman Murali Mohan ${ }^{\mathrm{a}}$, Madhavi Kadambi ${ }^{\mathrm{a}}$
}

Departments of anternal Medicine and

Pulmonology, ' Medicine, Mazumdar Shaw Medical Center, Narayana Health, Bangalore, India

Corresponding author. Vadivelu Tamilarasan, MBBS, DTCD, DNB, Department of Internal Medicine and Pulmonology, Mazumdar Shaw Medical Center, Narayana Health, Bangalore 560099, India. Tel: +91 9513327765;

fax: +918027832648

e-mail: tamilnine9@gmail.com

Received 24 January 2018

Accepted 11 April 2018

The Egyptian Journal of Internal Medicine 2018, 30:168-169
Dengue is known for its nonspecific onset and frequently can rapidly deteriorate into a range of feared systemic complications including hemorrhagic fever and shock syndromes. However, vocal cord hematomas associated with dengue fever are a rare presentation. Here, we describe a case of vocal cord hematoma in a patient with dengue and thrombocytopenia, highlighting this rare association, which has a potential to aggravate into a life-threatening complication. The patient was treated conservatively and made a complete recovery.

\section{Keywords:}

dengue, hematoma, hoarseness of voice, vocal cord

Egypt J Intern Med 30:168-169

(1) 2018 The Egyptian Journal of Internal Medicine $1110-7782$

\section{Introduction}

A vocal cord hematoma is a collection of blood within the vocal fold that occurs after rupture of blood capillaries. Vocal cord hemorrhage, even with small quantity of blood, can cause discernible voice changes [1]. Production of voice is due to vibration of two small, layered folds of tissue overlying a muscle along with a combination of muscles in and around the larynx by modulating airflow from the lungs. When a bleed into the vocal cord occurs, layers of vocal fold tissue become filled with blood from a ruptured blood vessel, which affects the vibration of vocal cord leading to a change in the quality of voice most often noticeable clinically as hoarseness. Early diagnosis of a vocal fold hemorrhage is very important because of several reasons: primarily, although small, they can result in airway compromise, and second, continuation of phonation with a hematoma can lead to continued bleeding and an irreversible scar of vocal fold and permanent voice change. Here, we describe a case of vocal cord hematoma in a patient with dengue fever and thrombocytopenia who presented with hoarseness of voice. The patient recovered uneventfully after voice rest, intravenous fluid replacement, and platelet transfusion.

\section{Case report}

A 36-year-old male patient presented with presented with the complaints of fever, generalized body pain, tiredness, and sore throat for 4 days. Fever was high grade and not associated with chills and rigors. A day before admission, he developed hoarseness of voice. At presentation, his temperature was $101^{\circ} \mathrm{F}$. He was hypotensive $(90 / 60 \mathrm{mmHg})$ and bradycardic
$(50 / \mathrm{min})$ with respiratory rate of $18 / \mathrm{min}$. Hematological parameters showed thrombocytopenia $\left(10000\right.$ cells $\left./ \mathrm{mm}^{3}\right)$ and leucopenia $\left(3100\right.$ cells $\left./ \mathrm{mm}^{3}\right)$. Dengue NS1 antigen was positive, liver enzymes and coagulation profile were within normal limits, and chest radiograph result was normal. In view of the voice change, we decided to involve the ENT surgical team. At this point of time, however, the patient was severely thrombocytopenic and so was managed supportively with platelet transfusions. A video laryngoscopy was performed after the patient's platelets improved, and we were certain of a lowered risk from spontaneous bleeding. The video laryngoscope (VL) showed a hematoma involving both the vocal cords and immediate subglottis (Fig. 1). He was advised a complete cessation of phonation and given voice rest. His general condition improved and became afebrile. Hemodynamically, the patient improved (platelet count, $70000 / \mathrm{mm}^{3}$ ) and was discharged at stable condition with advice to follow-up. After 2 weeks, the patient had recovered almost $90 \%$ of his voice, but he was not willing for repeat video laryngoscopy. His platelet count was $250000 / \mathrm{mm}^{3}$.

\section{Ethical statement}

An informed patient consent form has been obtained from the patient for academic publication.

This is an open access journal, and articles are distributed under the terms of the Creative Commons Attribution-NonCommercial-ShareAlike 4.0 License, which allows others to remix, tweak, and build upon the work non-commercially, as long as appropriate credit is given and the new creations are licensed under the identical terms. 
Figure 1

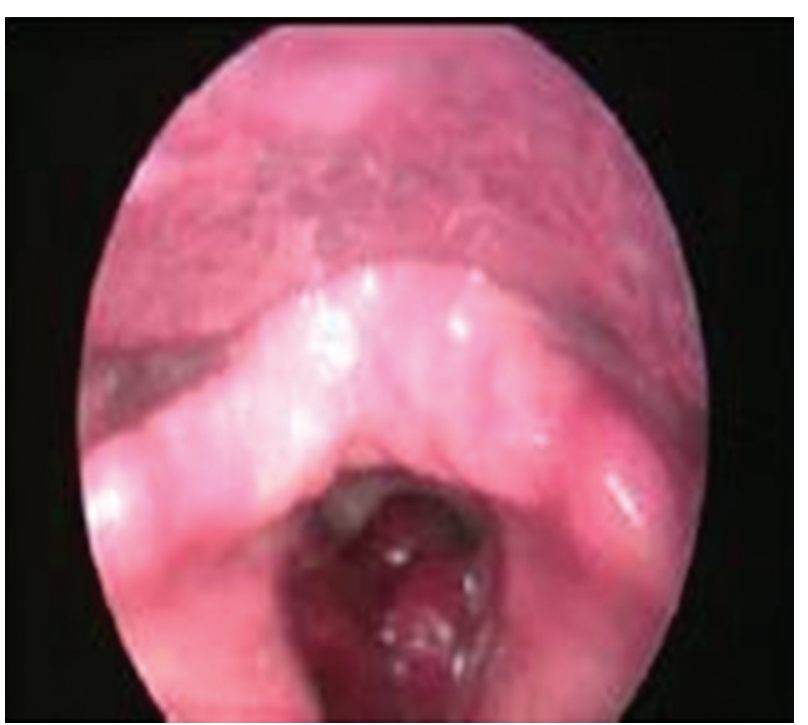

Hematoma involving bilateral vocal cords and immediate subglottis.

\section{Discussion}

There is now an unquestionable quantum of good quality evidence associating viral and/or dengue-associated thrombocytopenia with bleeding and subsequent hematoma formation [2]. Spontaneous hematomas secondary to dengue fever have been described in other sites like thorax, abdominal cavity, retroperitoneum, muscle parenchyma, joints, and rarely even lingual hematomas have been described [3-6]. A vocal cord hematoma due thrombocytopenia in a chronic myeloid leukemia has been reported in the literature [7]. To the best of our knowledge after extensive search, this is the first case of a vocal cord hematoma associated with dengue fever.

Within the vocal folds, there are extremely small tiny blood vessels that extend across the various tissue layers. Vocal cord hemorrhage results from the rupture of a submucosal blood vessel of the vocal fold, releasing blood which diffuses through the low-resistance tissue of the superficial layer of the lamina propria which disrupts the mechanical properties of this tissue, consequently resulting in changes in the vibratory parameters of the affected vocal folds. This can result in severe dysphonia [8]. There are numerous causes for vocal cord hematoma/hemorrhage such as trauma to the larynx after blunt force injury, phonotrauma, active upper respiratory tract infection, complication of medical or surgical procedure, hormonal imbalances, and use of anticoagulant among others [9].

In the present case, the hematoma was probably due to thrombocytopenia secondary to dengue fever. Platelet count during the time of hematoma was around 10000 cells $/ \mathrm{mm}^{3}$. Our patient, like the familiar presentation of other vocal cord-associated problems, presented with hoarseness of voice and vocal fatigue in addition to his viral prodromal symptoms. In this case, it is essential to establish the diagnosis of vocal cord hemorrhage definitively and early as, in view of the thrombocytopenia, if one continues to talk, further hemorrhage and scarring of the vocal fold layers may result leading to permanent voice changes [10]. Vocal cord hemorrhage can resolve spontaneously or can result in vocal cord polyp or a permanent vocal fold scar [1]. To conclude, in the absence of any other obvious causes for a vocal cord hematoma, we have concluded that the thrombocytopenia and phonotrauma have most likely resulted in vocal cord hemorrhage in our patient. It must be therefore emphasized that vocal cord hematomas should not be ruled out in patients who present with the background of an arboviral hemorrhagic fever and voice change until a laryngoscopic examination has been carried out satisfactorily after the patient's platelet counts have recovered to safe ranges.

\section{Acknowledgements}

The authors would like to thank V.M. Annapandian for his contribution toward technical editing of this report.

\section{Financial support and sponsorship \\ Nil.}

\section{Conflicts of interest}

There are no conflicts of interest.

\section{References}

1 Spiegel JR, Satalo VRT, Hawkshaw M, Rosen DC. Vocal fold hemorrhage. Ear Nose Throat J 1996; 75:784-789.

2 Nkoke C, Luchuo EB, Teuwafeu D, Nepetsoun I, Nkouonlack C. Chronic subdural hematoma associated with thrombocytopenia in a patient with human immunodeficiency virus infection in cameroon. Case Rep Neurol Med 2017; 2017:5395829.

3 Koshy JM, John M, Rathore S, George UB. Spontaneous muscle hematomas in a patient with dengue hemorrhagic fever. CHRISMED $J$ Health Res 2014; 1:201-202.

4 Sarkar J, Mohan C, Misra D, Goel A. Lingual hematoma causing upper airway obstruction: an unusual manifestation of dengue fever. Asian Pac $J$ Trop Med 2011; 4:412-413.

5 Sharma A, Bhatia S, Singh RP, Malik G. Dengue fever with rectus sheath hematoma: a case report. J Family Med Prim Care 2014; 3:159-160.

6 Singh J, Singh H, Sukhija G, Jagota R, Bala S. Retroperitoneal haematoma in a patient with dengue haemorrhagic fever: a rare case report. J Clin Diagn Res 2016; 10: OD01-OD02.

7 Shim $\mathrm{H}$, Woo S. Vocal fold hemorrhage in a CML patient after Glivec treatment. Acta Oncol (Madr) 2012; 52:866-868.

8 Anderson T, Hawkshaw M, Satalo VRT. Right posthemorrhagic polyp with vocal fold varices. Ear Nose Throat J 2002; 81:494.

9 Murry T, Rosen C. Phonotrauma associated with crying. J Voice 2000; 4:575-580.

10 Neely J, Rosen C. Vocal fold hemorrhage associated with coumadin therapy in an opera singer. J Voice 2000; 14: 272-277. 